\title{
Prevalence and correlates of depression, anxiety and stress among undergraduate pharmacy students in Nigeria
}

\author{
Deborah Oyine Aluh ${ }^{1}$ (D), Abubakar Abba ${ }^{1}$ (D), \& Afeez Babatunde Afosi ${ }^{2}$ \\ ${ }^{1}$ University of Nigeria Nsukka, Nigeria $\quad{ }^{2}$ University of Ilorin, Nigeria
}

\author{
Keywords \\ Depression \\ Anxiety \\ Stress \\ Pharmacy students \\ Nigeria
}

\section{Correspondence}

Deborah Oyine Aluh

Department of Clinical Pharmacy and

Pharmacy Management

University of Nigeria

Nsukka

410001

Nigeria

deborah.aluh@unn.edu.ng

\begin{abstract}
Background: Mental health disorders are increasingly becoming a global concern among university students. The prevalence of depression, anxiety and stress among pharmacy students in Nigeria is unknown. Objective: This study sought to examine the occurrence of depression, anxiety and stress and associated sociodemographic factors among undergraduate pharmacy students in Nigeria. Methods: The study was an online-based cross-sectional descriptive survey conducted among students from seven pharmacy schools in Nigeria. Students were recruited via their class WhatsApp groups and a link to a Google Form was provided for those who agreed to participate in the study. Data were analysed using IBM Statistical Product and Services Solution for Windows version 21.0. Results: A total of 408 students out of approximately 3,068 students responded to the survey (response rate: $13.32 \%$ ). The prevalence of depression, anxiety and stress was $44.6 \%, 63.5 \%$, and $35 \%$, respectively. Depression was found to be strongly correlated with stress ( $r=0.739$, $p<0.001)$ and anxiety $(r=0.715, p<0.001)$. Depression, anxiety and stress scores significantly correlated with perceived academic performance and year of study. There was no significant association between gender, cigarette smoking, type of accommodation, and the levels of depression, anxiety, and stress. Conclusion: The prevalence of depression, anxiety and stress among pharmacy students responding to a survey in Nigeria was high. Students in lower years of study and those with perceived poor academic performance had higher levels of depression, anxiety and stress. More studies are needed to explore the causes of depression, anxiety and stress among pharmacy students.
\end{abstract}

\section{Introduction}

Mental health disorders are regarded as one of the major causes of disability worldwide (Youssif, 2019). Depression and anxiety disorders have been ranked by the World Health Organisation (WHO) among the first six contributors to non-fatal health loss; accounting for $7.5 \%$ and $3.4 \%$ of global years of life lived with disability respectively (WHO, 2017). Mental health disorders occur in a substantial population of adults in Nigeria (Gureje et al., 2006a). The lifetime and 12-month prevalence of at least one DSM-IV disorder were about $12.5 \%$ and $5.6 \%$ respectively in a survey conducted by Gureje et al. (2006). Major depressive disorders were reported to have a lifetime and 12-month prevalence of $3.3 \%$ and $1.0 \%$ respectively. Anxiety disorders were most frequent with a lifetime prevalence of $5.7 \%$, and 12 -month prevalence of 4.1\% (Gureje et al., 2006). A higher prevalence of depression and anxiety of $5.5 \%$ and $3.5 \%$ were reported in a population study conducted in Lagos, Nigeria (Adewuya et al., 2018). Stress on the other hand has been reported 
to be high among working populations in Nigeria. The prevalence of psychosocial stress was $61.97 \%$ among health workers (Onigbogi \& Banerjee, 2019), and 72.2\% among teachers in Nigeria (Asa \& Lasebikan, 2016).

Human and infrastructural resources for the provision of mental health services are limited in low and middleincome countries (Saxena et al., 2007). In Nigeria, although the prevalence of mental health disorders is lower than the global prevalence (Adewuya et al., 2018), the mental health resources in the country do not match the mental health services' demand (Uwakwe, 2019). The WHO Assessment Instrument for Mental Health Systems (WHO-AIMS) report showed that mental health infrastructure was grossly inadequate in Nigeria and less than $5 \%$ of the health budget is allocated to mental health annually (WHO \& Federal Ministry of Health Nigeria, 2006). There was also an estimate of 0.09 psychiatrists and 0.4 mental health beds per 100,000 persons in Nigeria (Uwakwe, 2019). This huge deficit places a great deal of strain on the limited mental health structure in Nigeria and makes access to mental health services difficult in Nigeria. It was shown that about $90 \%$ of those who were found to have any form of mental disorder did not receive treatment for their condition (Gureje et al., 2006). Another related study also showed that only $9 \%$ of the study population with DSM-IV mental disorder had ever received treatment, of which only $1 \%$ was from a mental health specialty service. Also, none of the respondents in this study received minimally adequate treatment for their mental condition (Gureje \& Lasebikan, 2006).

Mental health disorders are increasingly becoming a global concern among university students. Young adults, who form the bulk of undergraduate university students, are vulnerable to mental illness (Othman et al., 2019) as the majority of mental disorders have their first onset within this age (Downs et al., 2018). This period also represents a critical transition stage for undergraduate students; with most of them becoming more independent in decision making and taking responsibility (Bayram \& Bilgel, 2008). Most of the students leave their home state to pursue university degrees and find themselves in a completely new environment, a transition which itself could cause anxiety, depression and stress (Beiter et al., 2015). Undergraduate studies are also associated with an increased workload, academic demands, and course work that require students to develop self-directed learning and the ability to make the best use of time (Callender et al., 2011). These combined academic, social and environmental changes place a higher demand on students which could be perceived as negative stress. Naturally, a fair level of pressure should serve as a motivation for students to meet academic demands. But when such pressure exceeds the students' ability to cope, stress will set in (Suleyiman \& Zewdu, 2018).

Several studies have documented the high rates of depression, anxiety and stress among undergraduate university students (Bayram \& Bilgel, 2008; Beiter et al., 2015). In a study by Suleyiman and Zewdu, (2018) a lifetime prevalence of stress of $24.5 \%$ was found among undergraduate students. A prevalence rate of $47.1 \%$ was reported for anxiety symptoms in a study conducted in Turkey (Bayram \& Bilgel, 2008). A systematic review of studies of the prevalence of depression in university students revealed that depression affected $10 \%-84 \%$ of undergraduate students (Ibrahim et al., 2013). These figures are an indication that mental disorders are a common occurrence among university students.

Students studying health-related courses have been the focus of many studies on mental health disorders and their associated factors. Studies have been carried out among medical (Fawzy \& Hamed, 2017; Tanaja, Sachdeva, \& Dwivedi, 2018; Kebede, Anbessie, \& Ayano, 2019; Yousif et al., 2019), nursing (Cheung et al., 2016) and pharmacy students (Gonçalves \& Figueiredo-braga, 2018; Sabourin, Prater, \& Mason, 2018). High levels of depression, anxiety and stress were found in these groups of students, which sometimes surpassed that of the general population (Sabourin, Prater, \& Mason, 2018). These groups of students share a common characteristic of studying health-related courses, and their curriculum is perceived to be more taxing than that of other university students.

The pharmacy curriculum, similar to other healthcare courses, is rigorous and intensive (Sabourin, Prater, \& Mason, 2018). Studies among undergraduate pharmacy students have revealed a substantial level of depression, anxiety and stress. Ibrahim \& Abdelreheem, (2019) found in their study that $29.3 \%$ and $51.1 \%$ of pharmacy students had depression and anxiety, respectively. In another recent study, over one-fourth of pharmacy students had high levels of depression, anxiety and stress (Sabourin, Prater, \& Mason, 2018). Perceived stress was also found to be high among pharmacy students (Sun \& Zoriah, 2015). Some studies have even reported a higher risk of stress in students studying pharmacy compared to students in other healthcare professions (Henning, Ey, \& Shaw, 1998). Pharmacy students attribute stress to various academic and social factors that affect their lives. Course work, lack of finance, inadequate sleep, and grades were the major stressors identified by pharmacy students in a nationwide survey conducted in the United States (Votta \& Benau, 2014). Pharmacy students in Ghana reported workload, laboratory report writing, lack of 
leisure time, and the pressure to excel in exams as the major perceived stressors (Opoku-Acheampong et al., 2017).

Poor mental health among undergraduate students could have a serious negative consequence on their academic and social life. Stress among undergraduate students has been associated with decreased cognitive ability leading to poor academic performance (Kötter et al., 2017; Frazier et al., 2019). Studies among pharmacy students showed that stress was negatively correlated with quality of life (Marshall, Allison, \& Nykamp, 2008; Eisenberg, Golberstein, \& Hunt, 2009; Opoku-Acheampong et al., 2017). Depression has also been shown to be negatively associated with academic performance among undergraduate students (Al-qaisy, 2011; Khanam \& Bukhari, 2015; Moreira de Sousa, Moreira, \& Telles-Correia, 2018). Depression and anxiety were also associated with poor sleep quality and deterioration in the quality of life (Cramer, Torgersen, \& Kringlen, 2005; Oh et al., 2019).

To cope with academic demands and several stressors within the university environment, some students resort to the use of stimulants such as energy drinks and coffee (Pettit \& DeBarr, 2011; Mahoney et al., 2019; Šabić \& Mujanović, 2019). Students may seek the benefits of coffee and other caffeine-containing drinks to stay awake at night to study for tests and exams, complete assignments, and stay alert and focused during lectures (Mcllvain, Noland, \& Bickel, 2011; Mahoney et al., 2019). In some cases, the urge to relieve stress could lead to cigarette smoking, alcohol consumption, and illicit drug use among students (Sohail, 2013; Oduaran \& Akanni, 2019). The use of substances such as marijuana and tobacco has also been associated with depression while anxiety has been associated with alcohol intake (Esmaeelzadeh et al., 2018).

In Nigeria, bachelor's programmes in sciences, social sciences, and humanities have a nominal duration of four years (Nuffic, 2009). However, the bachelor's programmes in the pharmaceutical sciences, medical and paramedical sciences, engineering, and law take between five to six years to complete (Onyukwu, Clark, \& Ausukuya, 2017). The pharmacy degree in Nigeria is currently a five-year course that culminates in the award of a Bachelor of Pharmacy (B.Pharm.) (Ogaji \& Ojabo, 2014). Undergraduate pharmacy students are expected to satisfy the minimum credit requirements in their course work, practical and hospital clerkship as stipulated by the Pharmacists Council of Nigeria, before they are awarded a B.Pharm. (Pharmacists Council of Nigeria, 2020). Most pharmacy schools in Nigeria are currently transitioning into the Doctor of Pharmacy curriculum, which is a six-year programme with additional emphasis on clinical skills that are the basis to understanding the diagnosis and treatment of diseases, and the therapeutic use of drugs (Ogaji \& Ojabo, 2014).

Mental health disorders among university students have been studied in Nigeria; with most of the studies focusing on medical students (Aniebue \& Onyema, 2008; Rasheed, 2016; Chinawa et al., 2018; Coker, Coker, \& Sanni, 2018). These studies revealed an alarming level of anxiety, depression and stress among undergraduate students in Nigeria. These findings are worrisome especially with the increased reports of suicide among university students in Nigeria, as a strong association has been found between suicidal ideation and anxiety, depression, and stress among university students (Izadinia et al., 2010).

Mental health disorders in pharmacy students have not received the needed attention in Nigeria (Adebisi et al., 2019). Studies carried out among other university students in Nigeria showed an unprecedented high prevalence of depression. However, no such studies have been carried out among pharmacy students. To fill this gap, the authors sought to examine the occurrence of depression, anxiety and stress and their association with socio-demographic factors among pharmacy students in Nigeria.

\section{Materials and Methods}

\section{Study design}

The study was an online cross-sectional descriptive survey conducted among undergraduate pharmacy students from seven universities in Nigeria. The study protocol was approved by the University of Nigeria institutional review committee.

\section{Study population and sampling technique}

Seven out of 20 accredited pharmacy schools in Nigeria, comprising three schools from the Southern region and four schools from the Northern region, were purposively selected for the study. WhatsApp, which is a messaging application, was used to recruit students for the study. A link to the study questionnaire was posted in the WhatsApp group of each of the professional classes (2nd 5 th years) of pharmacy students in the selected schools. The link to the study questionnaire was accompanied by a cover letter that explained the purpose of the survey to the respondents and assured them of confidentiality and anonymity. Students who agreed to participate in the study followed the link to fill the questionnaire on a Google Form. The study took place from April to 
September 2019. The link to the Google Form was posted bi-weekly in each of the class WhatsApp groups for the two-month duration of the study.

Because of the effectiveness of reminders in improving response rate (Van Mol, 2017; Harrison et al., 2019), class representatives were required to repost the invitation link for the study in their respective WhatsApp groups, on weekly basis throughout the study period. This served as a reminder to those who could not respond to the questionnaire earlier.

\section{Data collection and instrument}

Data were collected using a questionnaire in the form of an online Google Form. The use of an online data collection method was informed by its relative advantages over other methods of data collection. Traditional survey methods such as face-to-face surveys, telephone interview, and mail have some limitations ranging from high cost, wastage of paper, long travel, and time consumption both for researchers and respondents (Esmaeelzadeh et al., 2018). The use of online tools allows for timely access to participants in distant locations at a lower cost (Wright, 2006). The automated nature of online data collection also saves the researcher time for manual data entry (Wright, 2006). The Google Form used in this study is a free online tool for designing and developing a web-based questionnaire (Esmaeelzadeh et al., 2018). The prevalent use of smartphones and easy access to the internet among university students in Nigeria (Ani, 2010; Nwachukwu \& Onyenankeya, 2017) made online surveys a suitable option for data collection.

The study questionnaire consisted mainly of two sections: socio-demographic information and the 21 item version of the Depression, Anxiety and Stress Scale (DASS) (Basha \& Kaya, 2016). The sociodemographic section consisted of students' personal information such as gender, age, level of study, and accommodation type. The respondents were also asked about whether they had repeated a class previously. This was done to objectively assess students' academic performance. To provide a subjective assessment of academic performance, students were asked: 'What is your perception about your academic performance in the previous year?'. The question allowed a response using a 5-point Likert scale from 'excellent' to 'not very good'. To assess cigarette smoking, students were asked a dichotomous question of whether they currently smoke cigarettes or not. Finally, the respondents were also asked to describe their coffee intake on a 3-item Likert scale of 'regularly', 'sometimes' and 'never'.
The DASS is a self-administered three sub-scales questionnaire that is used to evaluate the psychological status of an individual (Basha \& Kaya, 2016). It is a 42 item questionnaire with a 4-point Likert scale, used to measure the level of depression, anxiety and stress among tested subjects (Basha \& Kaya, 2016). A short version of the 42 items DASS questionnaire is available and contains 21 items with seven items per sub-scale (Gomez, 2002). When completing the DASS questionnaire an individual is asked to indicate their experience of a given symptom in the preceding week on a 4-point Likert scale (Jafari et al., 2017). For example, a respondent reacts to the question ' found it difficult to work up the initiative to do things' with one of the following response: 'Did not apply to me at all' = 0; 'Applied to me some of the time' = 1 ; 'Applied to me good part of time' = 2; and 'Applied to me most of the time' = 3 (Jafari et al., 2017). The total score of depression, anxiety and stress are obtained by adding up the relevant items for each of the sub-scales and multiplied by two to reflect the original 42 item questionnaire (Jafari et al., 2017). For depression sub-scale, a score of 9 or less was considered normal, 10-13 as mild, $14-20$ as moderate, 21-27 as severe, and scores of 28 or more as extremely severe. For anxiety, a score of 7 or less was considered normal, 8-9 as mild, 10-14 as moderate, 15-19 as severe, and 20 or more as extremely severe. A stress score of 14 or less was considered normal, $15-18$ as mild, $19-25$ as moderate, 26-33 as severe, and a score of 34 or more was regarded as extremely severe (Lovibond \& Lovibond, 1995). The 21 item version of DASS was adopted for use in this study. The DASS questionnaire has been well used among undergraduate university students (Bayram \& Bilgel, 2008; Talwar, 2016; Penmetsa \& Seethalakshmi, 2019). The validity and reliability of the DASS questionnaire in measuring depression, anxiety and stress symptoms among university students have been confirmed in many studies (Talwar, 2016; Lee, 2019).

\section{Data analysis}

Data were entered into IBM Statistical Product and Services Solution (SPSS) for Windows v. 21.0 for analysis. Similar to previous studies (Coker, Coker, \& Sanni, 2018; Herrmann et al., 2019), a score representing mild severity or more on the DASS questionnaire was used as the cutoff point for depression, anxiety and stress and was used to determine their prevalence. Relevant descriptive statistics such as frequencies and percentages were carried out for the prevalence and severity of anxiety, depression and stress, as well as socio-demographic characteristics. 
Kruskal-Wallis H-test was employed in the data analysis. It is a non-parametric analog of one way ANOVA test, that is used to ascertain whether a relationship exists between two variables when one is nominal and the other is either ordinal, interval or ratio (Plichta \& Kelvin, 2013). Spearman correlation was used to test the strength and direction of the association between the DASS scores and sociodemographic characteristics with $p$-value $<0.05$ set as the level of significance.

\section{Results}

A total of 408 students out of approximately 3068 students responded to the survey (Response rate: $13.32 \%)$.

Table I: Sociodemographic characteristics of respondents

\begin{tabular}{|c|c|c|}
\hline Characteristics & Frequency (n) & Percentage (\%) \\
\hline \multicolumn{3}{|l|}{ Gender } \\
\hline Male & 201 & 49.3 \\
\hline Female & 207 & 50.7 \\
\hline \multicolumn{3}{|l|}{ Year of Study } \\
\hline Second Year & 60 & 14.7 \\
\hline Third Year & 93 & 22.8 \\
\hline Fourth Year & 120 & 29.4 \\
\hline Fifth Year & 135 & 33.1 \\
\hline \multicolumn{3}{|l|}{ Accommodation type } \\
\hline School hostel & 197 & 48.3 \\
\hline Alone off-campus & 163 & 40.0 \\
\hline With parents/relatives & 48 & 11.8 \\
\hline \multicolumn{3}{|l|}{ Repeated a class in the past } \\
\hline Yes & 100 & 24.5 \\
\hline No & 308 & 75.5 \\
\hline \multicolumn{3}{|c|}{ Perceived academic performance in the previous year } \\
\hline Not very good & 20 & 4.9 \\
\hline Not as good as I expected & 65 & 15.9 \\
\hline Average & 137 & 33.6 \\
\hline Very good & 151 & 37.0 \\
\hline Excellent & 35 & 8.6 \\
\hline \multicolumn{3}{|l|}{ Cigarette smoking } \\
\hline Yes & 9 & 2.2 \\
\hline No & 399 & 97.8 \\
\hline \multicolumn{3}{|l|}{ Coffee intake } \\
\hline Regularly & 35 & 8.6 \\
\hline Sometimes & 230 & 56.4 \\
\hline Never & 143 & 35.0 \\
\hline
\end{tabular}

\section{Socio-demographic characteristics of respondents}

The study population consisted of an almost equal number of males $(201,49.3 \%)$ and females $(207,50.7 \%)$ with an average age of $22.57 \pm 3.39$. Most of the students were in their fifth-year of study $(135,33.1 \%)$ and were residing in school hostels $(197,48.3 \%)$. Most of the students had not repeated a class in the past (308, 75.5\%) and perceived their previous year's academic performance to be very good $(151,37.5 \%)$. When asked about cigarette smoking and coffee intake, the majority of the students indicated that they were not smoking cigarettes (399, $97.8 \%)$, but more than half of them $(230,56.4 \%)$ take coffee sometimes (Table I).

Table II: Prevalence and severity of depression, anxiety and stress among respondents

\begin{tabular}{lccc}
\hline Severity & $\begin{array}{c}\text { Depression } \\
\mathbf{n}(\%)\end{array}$ & $\begin{array}{c}\text { Anxiety } \\
\mathbf{n}(\%)\end{array}$ & $\begin{array}{l}\text { Stress } \\
\mathbf{n}(\%)\end{array}$ \\
\hline Normal & $226(55.4)$ & $149(36.5)$ & $265(65.0)$ \\
Mild & $70(17.2)$ & $90(22.1)$ & $63(15.4)$ \\
Moderate & $75(18.4)$ & $76(18.6)$ & $49(12.0)$ \\
Severe & $20(4.9)$ & $36(8.8)$ & $25(6.1)$ \\
Extremely severe & $17(4.2)$ & $57(14.0)$ & $6(1.5)$ \\
\hline
\end{tabular}

\section{Prevalence and severity of depression, anxiety, and stress} among respondents

The overall prevalence of depression, anxiety and stress was $44.6 \%, 63.5 \%$, and $35 \%$ respectively. Severe depression, anxiety and stress prevalence was $4.9 \%$, $8.8 \%$, and $6.1 \%$ respectively. While $4.2 \%, 14.0 \%$, and $1.5 \%$ of the students had extremely severe depression, anxiety, and stress (Table II).

\section{Correlation between respondents' characteristics and depression, anxiety and stress.}

There was a significant negative correlation between depression and the year of study, perceived academic performance, having repeated a class, and age. There was also a significant negative correlation between anxiety and level of study, perceived academic performance, coffee intake, and age. While, stress was negatively correlated with the level of study, perceived academic performance, and age (Table III). 
Table III: Correlation between respondents' characteristics and depression, anxiety and stress

\begin{tabular}{lccc}
\hline Characteristics & $\begin{array}{c}\text { Depression } \\
\mathbf{r}_{\mathbf{s}}(\mathbf{p})\end{array}$ & $\begin{array}{c}\text { Anxiety } \\
\mathbf{r}_{\mathrm{s}}(\mathbf{p})\end{array}$ & $\begin{array}{c}\text { Stress } \\
\mathbf{r}_{\mathrm{s}}(\mathbf{p})\end{array}$ \\
\hline Year of study & -0.251 & -0.290 & -0.239 \\
& $(0.000)^{* *}$ & $(0.000)^{* *}$ & $(0.000)^{* *}$ \\
\hline Accommodation type & 0.013 & 0.021 & 0.008 \\
& $(0.795)$ & $(0.667)$ & $(0.866)$ \\
\hline Have repeated a class & -0.137 & -0.082 & -0.080 \\
\hline Perceived academic & $(0.006)^{* *}$ & $(0.099)$ & $(0.108)$ \\
performance & -0.251 & -0.216 & -0.167 \\
\hline Coffee intake & $(<0.001)^{* *}$ & $(0.001)^{* *}$ & $(0.001)^{* *}$ \\
\hline Age & -0.079 & -0.127 & -0.033 \\
& $(0.109)$ & $(0.010)^{*}$ & $(0.508)$ \\
\hline Depression & -0.139 & -0.137 & 0.125 \\
& $(0.005)^{* *}$ & $(0.006)^{* *}$ & $(0.011)^{*}$ \\
\hline Anxiety & 1 & 0,625 & 0.575 \\
& & $(<0.001)$ & $(<0.001)$ \\
\hline Stress & 0.625 & 1 & 0.647 \\
& $(<0.001)$ & & $(<0.001)$ \\
\hline Corre & 0.575 & 0.647 & 1 \\
\hline
\end{tabular}

${ }^{*}$ Correlation is significant at the 0.05 level

${ }^{* *}$ Correlation is significant at the 0.01 leve

Table IV: Association between DASS scores and students' sociodemographic characteristics

\begin{tabular}{|c|c|c|c|}
\hline \multirow[b]{2}{*}{ Grouping variable } & \multicolumn{3}{|c|}{ Kruskal-Wallis test mean rank } \\
\hline & Depression & Anxiety & Stress \\
\hline \multicolumn{4}{|l|}{ Year of Study } \\
\hline Second Year & 246.58 & 263.23 & 249.53 \\
\hline Third Year & 232.77 & 231.09 & 242.31 \\
\hline Fourth Year & 211.36 & 202.15 & 200.40 \\
\hline Fifth Year & 160.22 & 162.17 & 162.09 \\
\hline$p$-value & $<0.001^{*}$ & $<0.001^{*}$ & $<0.001^{*}$ \\
\hline \multicolumn{4}{|l|}{ Accommodation type } \\
\hline School hostel & 207.68 & 206.78 & 210.42 \\
\hline Alone off-campus & 195.62 & 193.83 & 192.21 \\
\hline With parent/relative & 221.64 & 231.36 & 221.96 \\
\hline$p$-value & 0.350 & 0.140 & 0.188 \\
\hline \multicolumn{4}{|c|}{ Perceived academic performance } \\
\hline Not very good & 278.08 & 263.88 & 254.58 \\
\hline Not as good as I expected & 240.68 & 237.00 & 238.95 \\
\hline Average & 224.72 & 219.46 & 225.15 \\
\hline Very good & 163.13 & 173.45 & 173.04 \\
\hline Excellent & 194.63 & 185.63 & 166.81 \\
\hline$p$-value & $<0.001^{*}$ & $<0.001^{*}$ & $<0.001^{*}$ \\
\hline \multicolumn{4}{|l|}{ Coffee Intake } \\
\hline Regularly & 249.07 & 270.56 & 258.01 \\
\hline Sometimes & 203.44 & 200.47 & 195.21 \\
\hline Never & 195.30 & 194.82 & 206.34 \\
\hline \multirow[t]{2}{*}{$p$-value } & 0.051 & $0.002^{*}$ & $0.013^{*}$ \\
\hline & \multicolumn{3}{|c|}{ Mann-Whitney mean rank } \\
\hline \multicolumn{4}{|l|}{ Gender } \\
\hline Male & 203.70 & 206.88 & 205.32 \\
\hline Female & 205.28 & 202.19 & 203.71 \\
\hline$p$-value & 0.892 & 0.687 & 0.890 \\
\hline \multicolumn{4}{|l|}{ Smoking status } \\
\hline Yes & 247.17 & 275.61 & 234.00 \\
\hline No & 203.54 & 202.90 & 203.83 \\
\hline$p$-value & 0.27 & 0.066 & 0.446 \\
\hline
\end{tabular}

\section{Association between DASS scores and students' socio- demographic characteristics}

Depression was found to be strongly correlated with stress $(r=0.739, p<0.001)$ and anxiety $(r=0.715, p<0.001)$. Kruskal-Wallis test showed that depression, anxiety and stress scores were significantly higher in students with poor perceived academic performance, and students in lower years of study. Anxiety and stress scores were significantly different between students who never took a coffee and those that took it sometimes and regularly (Table IV). The result, however, showed no significant association between gender and the level of depression anxiety and stress, although a greater proportion of females had extremely severe stress $(66.7 \%, n=4)$, extremely severe depression $(64.7 \%, n=11)$ and extremely severe anxiety $(52.6 \%, n=30)$. There was also no significant association between cigarette smoking and depression, anxiety and stress.

\section{Discussion}

This study set out to assess depression, anxiety and stress, and their associated socio-demographic factors among pharmacy students in Nigeria. A low response rate of $13.32 \%$ was recorded in this study. This may be attributed to the use of a web-based questionnaire which is still a novel tool for data collection in Nigeria (Ajumobi et al., 2018). Although previous studies have demonstrated a lower response rate to a web-based questionnaire compared to a paper-based questionnaire (Ebert et al., 2018; Harrison et al., 2019); online data collection has been successfully used among university students in other countries with response rates as high as 90\% (Mirón et al., 2019; Othman, 2019). Despite the proven effect of incentives on improving response rate (Edwards et al., 2009; Pedersen \& Nielsen, 2016), its cost implications could not allow for its use in this study (Olsen, Abelsen, \& Olsen, 2012). Nonetheless, this research work explored the online method of recruitment and data collection, an approach which is still novel in Nigeria. To ensure a better response rate, future studies of this nature can explore the use of incentives such as cash prize or non-monetary incentives such as lottery tickets. These methods although more costly (Olsen, Abelsen, \& Olsen, 2012) have proven to significantly improve response rate (Ryu, Couper, \& Marans, 2006; Edwards et al., 2009; Olsen, Abelsen, \& Olsen, 2012) and also reduce item non-responsiveness (Olsen, Abelsen, \& Olsen, 2012).

The prevalence of depression, anxiety and stress in this study were reported to be $44.6 \%, 63.5 \%$, and $35 \%$ respectively. These prevalence rates were higher than the 
population prevalence of depression and anxiety in Nigeria (Gureje, 2006). The reported prevalence of depression and anxiety were respectively lower and higher than those reported in a similar study among pharmacy students in Alexandria University (Ibrahim \& Abdelreheem, 2019). The Egyptian study reported that the prevalence of depression and anxiety among pharmacy students was $51.1 \%$ and $29.3 \%$ respectively. A possible reason for this difference may be because this study recruited students from different pharmacy schools in Nigeria, while the Egyptian study was restricted to pharmacy students from one institution. Ibrahim and Abdelraheem (2019) also reported that the prevalence of depression and anxiety among pharmacy students was lower than that of their medical colleagues. This study, however, reported a higher prevalence of these disorders among pharmacy students compared to studies conducted among medical students in Nigeria (Coker, Coker, \& Sanni, 2018). The reported prevalence in this study was also higher than the pooled stress prevalence of $25.2 \%$ reported in a meta-analysis of depression, anxiety and stress among medical students in Nigeria (Esan et al., 2019).

The study findings did not show significant gender disparity in self-reported depression, anxiety and stress among pharmacy students. The finding of non-gender disparity of depression score in the study concurs with that of a previous study among pharmacy students at the University of Michigan (Sabourin, Prater, \& Mason, 2018). It is also in keeping with the results of the Nigerian mental health survey that found no significant gender difference in the prevalence of depression at the population level (Gureje et al., 2010). This is in contrast with the findings from the study by Adewuya and colleagues (2006) where female students were twice as likely to have depression (Adewuya et al., 2006). The gender similarity in anxiety and stress scores in pharmacy students also contradict the most reported findings of a greater prevalence of stress and anxiety among female university students (Aniebue \& Onyema, 2008; Stallman, 2010; Hanna et al., 2018; Sabourin, Prater, \& Mason, 2018; Herrmann et al., 2019). Some studies hypothesised that men see the expression of stress as a sign of weakness, which may explain its lower prevalence among them (Shaikh et al., 2004). Other studies, however, agree with the findings in this study. A study carried out among students of a medical school in Malaysia did not find any significant gender difference in anxiety and stress of the students (Sun \& Zoriah, 2015). A similar study conducted in Nigeria also did not find any significant gender difference in the prevalence of depression, anxiety and stress (Coker, Coker, \& Sanni, 2018).
The authors found a significant difference in the levels of depression, anxiety and stress scores across years of study. Students in the final year had lower levels of depression compared to those in the lower year classes. The pharmacy curriculum in Nigeria was designed to contain fewer courses and exams in the final year of study. Fewer courses and exams usually result in reduced student workload that provides time for self-maintenance and eventually fewer health problems (Votta \& Benau, 2014). A similar study among undergraduate pharmacy students also showed that final-year students had a lower level of stress than those in lower classes (Votta \& Benau, 2014). These findings are however in contrast with other studies that found no significant association between the level of depression, anxiety and stress with the year of study (Rasheed, 2016; Opoku-Acheampong et al., 2017;). The variation in depression, anxiety and stress scores across years of study is an indicator that students at different years of study may require unique mental health services to meet their particular mental health needs. Such variations should guide the design and implementation of mental health programmes among pharmacy students. While previous studies found a strong correlation between the type of accommodation and depression, anxiety and stress levels in undergraduate students, the findings from this study could not establish any association. A previous study found that students staying off-campus had a greater level of depression, anxiety and stress when compared to their colleagues that stay within the hostel accommodation (Beiter et al., 2015). Beiter et al. (2015) argued that factors likely influencing this outcome are the fact that students that stay off-campus are exposed to additional stressful experiences such as paying monthly rent and dealing with problems that may arise in their accommodation. Most Nigerian universities, however, have serious accommodation problems (Adewuya et al., 2006). A study in some Nigerian universities showed that an average of six - eight persons stayed per room in the University's halls of residence (Adewuya et al., 2006). This is because about $40 \%$ of students in the halls of residence were unofficially squatting with their fellow students (Adewuya et al., 2006). This could make living conditions within the University hostel as stressful as the off-campus accommodation and could explain the similarities in depression anxiety and stress scores. This study's findings are corroborated by findings of a similar study among university students in Nigeria that showed no significant difference between students living within the university hostel and those living off-campus (Rasheed, 2016). 
The perceived academic performance can be a source of concern for pharmacy students. Academic performance is the yardstick that is used to determine the progress of students and when they graduate. Academic performance and pressure to succeed are some of the most common sources of worry to university students, and these concerns have been found to positively correlate with levels of depressive, anxiety and stress symptoms (Beiter et al., 2015). In the authors' study, students who believed they had better academic performance in the previous year had lower depression, anxiety and stress scores. This finding is similar to those found among medical students in Romania and Ethiopia (lorga, Dondas, \& Zugun-Eloae, 2018; Zegeye et al., 2018). Similar studies among undergraduate students have also demonstrated the negative effect of depression and anxiety on academic performance (Eisenberg, Golberstein, \& Hunt, 2009; Al-qaisy, 2011; Sohail, 2013; Khanam \& Bukhari, 2015; Opoku-Acheampong et al., 2017). Focused mental health services for students with poor academic performance will, therefore, be necessary to help alleviate the possible effects of mental health disorders.

A low level of caffeine intake has been shown to positively reinforce mood and performance (Haskell et al., 2005), and university students cite stress as one the reasons for their caffeinated drinks intake (Mahoney et al., 2019). Studies have established an increased risk of anxiety in coffee takers (Jin et al., 2016), and caffeine intake has been found to be positively associated with anxiety (Richards \& Smith, 2015). In agreement with the above studies, this study's results show that pharmacy students taking coffee regularly had a significantly greater level of anxiety and stress than those that take it sparingly, or do not take it at all. This finding, however, contradicts that of a similar study that found no association between stress and intake of caffeinated drinks (Cruz et al., 2013). The level of depression and stress were consistently higher among smokers, although the difference was not statistically significant. This shows that smoking among pharmacy students may be associated with factors other than stress and anxiety. The use of cigarettes among pharmacy students could be to enhance their interaction with peers during social events, to facilitate greater concentration, and to celebrate the completion of school events such as exams as used among other university students (Nichter, Nichter, \& Carkoglu, 2007; Nichter et al., 2010). This study's results contradict the finding from another study among university students where it was shown that smoking was positively associated with perceived levels of stress (Naquin \& Gilbert, 1996). It also contradicts the finding that depression was higher among university students who smoke tobacco (Vukomanovic et al., 2017). The level of anxiety of smokers and nonsmokers was not found to be significantly different. This sharply contrasts with the findings of a study among adolescent college students, that showed smokers exhibited a higher level of anxiety than non-smokers (Saravanan \& Heidhy, 2014). This was not expected as previous studies have shown that smoking was associated with more anxiety and stress instead of helping smokers relax (Collins \& Lepore, 2009; Herrmann et al., 2019).

\section{Strengths and limitations}

The strength of this study lies in the use of a standard validated questionnaire, online recruitment and the use of multiple pharmacy schools that were spread across the regions of the country. Some limitations should be carefully considered while interpreting the findings of this study. This study was cross-sectional and therefore only provides us with a point prevalence of depression, anxiety and stress symptoms among pharmacy students. The study was carried out at a time when some of the pharmacy schools included in the study were taking examinations, this may have influenced students' perceived level of depression, stress and anxiety. The DASS questionnaire used in this study uses a self-reported method of assessment by asking participants of their experience in the preceding week. The findings of the DASS questionnaire, like all other self-reported tools, should be interpreted while bearing in mind the possibility of information and recall bias. Also, the relatively low response rate recorded in the study can increase the chances of non-response bias which may, in turn, affect the generalisability of the study findings.

\section{Conclusion}

This is the first attempt at providing an insight into the mental health status of pharmacy students in Nigeria. The prevalence of depression, anxiety and stress among pharmacy students was found to be high in this study. Depression, anxiety and stress were found to be inversely associated with the year of study and perceived academic performance. These call for urgent attention, considering the negative impact that mental health disorders have on students' academic performance and their general wellbeing. These findings should also prompt university authorities and the Pharmacists Council of Nigeria, to have an in-depth look into mental health services 
provision in pharmacy schools. Future studies should investigate the availability, and provision of mental health support services in Nigerian institutions of learning, particularly among pharmacy students. There is also a need for more studies to explore the perceived causes of depression, anxiety and stress among pharmacy students and the relationship between these factors. Studies should also explore pharmacy students' opinions on suitable interventions for their mental health problems. This will guide the development of mental health programmes that will suit the particular needs of pharmacy students in Nigeria.

\section{References}

Adebisi, Y.A., Olaoye, O.C., Ekpenyong, A.M., Alaran, A.J., \& Lucero-Prisno III, D.E. (2019). Depression Among Pharmacy Students in Nigeria: Is It a Neglected Issue? Strides in Development of Medical Education, 16(1), e97918. https://doi.org/10.5812/ $\underline{\text { sdme. } 97918}$

Adewuya, A.O., Ola, B.A., Aloba, O.O., Mapayi, B.M., \& Oginni, O.O. (2006). Depression amongst Nigerian university students: Prevalence and sociodemographic correlates. Social Psychiatry and Psychiatric Epidemiology, 41, 674-678. https://doi.org/ 10.1007/s00127-006-0068-9

Adewuya, A.O., Atilola, O., Ola, B.A., Coker, O.A., Zachariah, M.P., Olugbile, O., et al. (2018). Current prevalence, comorbidity and associated factors for symptoms of depression and generalised anxiety in the Lagos State Mental Health Survey (LSMHS), Nigeria. Comprehensive Psychiatry, 81, 60-5. https://doi.org/10.1016/ j.comppsych.2017.11.010

Ajumobi, O., Uhomoibhi, P., Onyiah, P., Babalola, O., Sharafadeen, S., Ughasoro, M.D., et al. (2018). Setting a Nigeria national malaria operational research agenda: The process. BMC Health Services Research, 18(459). https://doi.org/10.1186/s12913-018-3224-5

Al-qaisy, L.M. (2011). The relation of depression and anxiety in academic achievement among group of university students. International Journal of Psychology and Counselling. 3(5), 96-100

Ani, O.E. (2010). Internet access and use: A study of undergraduate students in three Nigerian universities. The Electronic Library, 28(4), 555-67. https://doi.org/10.1108/0264047 $\underline{1011065373}$

Aniebue, P.N., \& Onyema, G.O. (2008). Prevalence of depressive symptoms among Nigerian medical undergraduates. Tropical Doctor, 38(3), 157-8. https://doi.org/10.1258/td.2007.070202

Asa, F.T., \& Lasebikan, V.O. (2016). Mental Health of Teachers: Teachers' Stress, Anxiety and Depression among Secondary Schools in Nigeria. International Neuropsychiatric Disease Journal, 7(4), 1-10. https://doi.org/10.9734/INDJ/2016/27039
Basha, E., \& Kaya, M. (2016). Depression, Anxiety and Stress Scale (DASS): The Study of Validity and Reliability. Universal Journal of Educational Research, 4(12), 2701-5. https://doi.org/10.13189/ ujer.2016.041202

Bayram, N., \& Bilgel. N. (2008). The prevalence and sociodemographic correlations of depression, anxiety and stress among a group of university students. Social Psychiatry and Psychiatric Epidemiology, 43, 667-672. https://doi.org/10.1007/s00127-008$\underline{0345-x}$

Beiter, R., Nash, R., McCrady, M., Rhoades, D., Linscomb, M., Clarahan, M., \& Sammut, S. (2015). The prevalence and correlates of depression , anxiety, and stress in a sample of college students. Journal of Affective Disorders, 173, 90-6. https://doi.org/10.1016/ j.jad.2014.10.054

Callender, J., Fagin, L., Jenkins, G., Lester, J. (2011). Mental health of students in higher education. College report CR 166. Royal College of Psychiatrists. Available at: https://www.rcpsych.ac.uk/ docs/default-source/improving-care/better-mh-policy/collegereports/college-report-cr166.pdf?sfursn=d5fa2c24 2

Cheung, T., Wong, S.Y., Wong, K.Y., Law, L.Y., Ng, K., Tong, M.T.,Wong, K.U., Ng, M.Y., \& Yip, P.S.F. (2016). Depression, anxiety and symptoms of stress among baccalaureate nursing students in Hong Kong: A cross-sectional study. International Journal of Environmental Research and Public Health, 13(8), 779. https:// doi.org/10.3390/ijerph13080779

Chinawa, A.T., Chinawa, J.M., Aniwada, E., Amadi, O., Ndukuba, A.C., \& Uwaezuoke, S.N. (2018). Spectrum of Anxiety Disorders Among Medical Students in a Nigerian Medical School: A CrossSectional Study With Standardized Screening Tools. Journal of Educational and Development Psychology, 8(2), 132. https:// doi.org/10.5539/jedp.v8n2p132

Coker, A.O., Coker, O.O., \& Sanni, D. (2018). Sociodemographic Correlates and Symptoms of Depression, Anxiety and Stress among a Sample of Nigerian Medical Students. Nigerian Journal of Basic and Clinical Sciences, 15(1), 58-62. https://doi.org/10.4103/ njbcs.njbcs 5016

Collins, B.N., \& Lepore, S.J. (2009). Association between anxiety and smoking in a sample of urban black men. Journal of Immigration and Minority Health, 11(1), 29-34. https://doi.org/ $\underline{10.1007 / s 10903-008-9164-0}$

Cramer, V.C., Torgersen, S., \& Kringlen, E. (2005). Quality of life and anxiety disorders: A population study. The Journal of Nervous and Mental Disease, 193(3), 196-202. https://doi.org/ 10.1097/01.nmd.0000154836.22687.13

Cruz, S.Y., González, A.M., González, M.J., Rivera-Soto, W.T., Palacios, C. (2013). Academic load, Academic stress, Caffeinated beverages. Puerto Rico Health Sciences Journal, 32(2), 95-100.

Downs, N., Galles, E., Skehan, B., \& Lipson, S.K. (2018). Be True to Our Schools-Models of Care in College Mental Health. Current Psychiatry Reports, 20(72). https://doi.org/10.1007/s11920-018-0935-6 
Ebert, J.F., Huibers, L., Christensen, B., \& Christensen, M.B. (2018). Paper-or web-based questionnaire invitations as a method for data collection: Cross-sectional comparative study of differences in response rate, completeness of data, and financial cost. Journal of Medical Internet Research, 20(1). https://doi.org/10.2196/jmir. $\underline{8353}$

Edwards, P.J., Roberts, I., Clarke, M.J., DiGuiseppi, C., Wentz, R., Kwan, I., Cooper, R., Felix, L.M., \& Pratap, S. (2009). Methods to increase response to postal and electronic questionnaires. Cochrane Database of Systematic Reviews, 3(MR000008). https:// doi.org/10.1002/14651858.MR000008.pub4

Eisenberg, D., Golberstein, E., \& Hunt, J.B. (2009). Mental Health and Academic Success in College. B.E Journal of Economic Analysis and Policy, 9(1), 1-40. https://doi.org/10.2202/1935-1682.2191

Esan, O., Esan, A., Folasire, A., \& Oluwajulugbe, P. (2019). Mental health and wellbeing of medical students in Nigeria: a systematic review. International Review of Psychiatry, 31(7-8), 661-72. https://doi.org/10.1080/09540261.2019.1677220

Esmaeelzadeh, S., Moraros, J., Thorpe, L., \& Bird, Y. (2018). The association between depression, anxiety and substance use among Canadian post-secondary students. Neuropsychiatric Disease and Treatment, 14, 3241-51. https://doi.org/10.2147/ NDT.S187419

Fawzy, M., \& Hamed, S.A. (2017). Prevalence of psychological stress, depression and anxiety among medical students in Egypt. Psychiatry Research, 255, 186-94. https://doi.org/10.1016/ j.psychres.2017.05.027

Frazier, P., Gabriel, A., Merians, A., \& Lust, K. (2019). Understanding stress as an impediment to academic performance. Journal of American College Health, 67(6), 562-70. https://doi.org/ 10.1080/07448481.2018.1499649

Gomez, F. (2002). A Guide to the Depression, Anxiety and Stress Scale (DASS 21)-Consultant Clinical Psychologist. Black Dog Inst. (Dass 21), 3

Gonçalves, R., \& Figueiredo-braga, M. (2018). Evaluation of the relationships among happiness, stress, anxiety, and depression in pharmacy students. Currents in Pharmacy Teaching and Learning, 10(7), 903-910. https://doi.org/10.1016/j.cptl.2018.04.002

Gureje, O., \& Lasebikan, V.O. (2006). Use of mental health services in a developing country. Results from the Nigerian survey of mental health and well-being. Social Psychiatry and Psychiatric Epidemiology, 41, 44-49.https://doi.org/10.1007/s00127-005-0001-7

Gureje, O., Lasebikan, V.O., Kola, L., \& Makanjuola, V.A. (2006). Lifetime and 12-month prevalence of mental disorders in the Nigerian Survey of Mental Health and Well-Being. The British Journal of Psychiatry, 188(5), 465-71. https://doi.org/10.1192/bjp.188.5.465

Gureje, O., Uwakwe, R., Oladeji, B., Makanjuola, V.O., \& Esan, O. (2010). Depression in adult Nigerians: Results from the Nigerian Survey of Mental Health and Well-being. Journal of Affective Disorders, 120(1-3), 158-64. https://doi.org/10.1016/j.jad.2009.04.030
Hanna, L.-A., Melissa, W., Maurice, H., \& Hanna, A. (2018). Pharmacists by Gender and Year Group. Pharmacy, 6(75). https:// doi.org/10.3390/pharmacy6030075

Harrison, S., Henderson, J., Alderdice, F., \& Quigley, M.A. (2019). Methods to increase response rates to a population-based maternity survey: A comparison of two pilot studies. BMC Medical Research Methodology, 19(65). https://doi.org/10.1186/ s12874-019-0702-3

Haskell, C.F., Kennedy, D.O., Wesnes, K.A., \& Scholey, A.B. (2005). Cognitive and mood improvements of caffeine in habitual consumers and habitual non-consumers of caffeine. Psychopharmacology, 179, 813-25. https://doi.org/10.1007/ s00213-004-2104-3

Henning, K., Ey, S., \& Shaw, D. (2002). Perfectionism, the impostor phenomenon and psychological adjustment in medical, dental, nursing and pharmacy students. Medical Education, 32(5), 456-64. https://doi.org/10.1046/i.1365-2923.1998.00234.x

Herrmann, K., Déchelotte, P., Ladner, J., \& Tavolacci, M.P. (2019). Depression, anxiety stress and associated factors among university students in France. European Journal of Public Health, 29(4). https://doi.org/10.1093/eurpub/ckz186.555

Ibrahim, A.K., Kelly, S.J., Adams, C.E., \& Glazebrook, C. (2013). A systematic review of studies of depression prevalence in university students. Journal of Psychiatric Research, 47(3), 391-400. https:// doi.org/10.1016/i.jpsychires.2012.11.015

Ibrahim, M.B., \& Abdelreheem, M.H. (2015). Prevalence of anxiety and depression among medical and pharmaceutical students in Alexandria University Prevalence of anxiety and depression among medical and pharmaceutical students in Alexandria. Alexandria Journal of Medicine, 51(2), 167-73. https://doi.org/10.1016/i.ajme. 2014.06.002

lorga, M., Dondas, C., \& Zugun-Eloae, C. (2018). Depressed as freshmen, stressed as seniors: The relationship between depression, perceived stress and academic results among medical students. Behavioral Sciences (Basel), 8(8). https://doi.org/ $10.3390 / \mathrm{bs} 8080070$

Izadinia, N., Amiri, M., Jahromi, R.G., \& Hamidi, S. (2010). A study of relationship between suicidal ideas, depression, anxiety, resiliency, daily stresses and mental health among Tehran university students. Procedia - Social Behavioral Sciences, 5, 1615-9. https://doi.org/10.1016/i.sbspro.2010.07.335

Jafari, P., Nozari, F., Ahrari, F., \& Bagheri, Z. (2017). Measurement invariance of the Depression Anxiety Stress Scales-21 across medical student genders. International Journal of Medical Education, 8, 116-22. https://doi.org/10.5116/ijme.58ba.7d8b

Jin, M.J., Yoon, C.H., Ko, H.J., Kim, H.M., Kim, A.S., Moon, H.N., \& Jung, S.-P. (2016). The relationship of caffeine intake with depression, anxiety, stress, and sleep in Korean adolescents. Korean Journal of Family Medicine, 37(2), 111-6. https://doi.org/ 10.4082/kjfm.2016.37.2.111 
Pedersen, M.J., \& Nielsen, C.V. (2016). Improving survey response rates in online panels: effects of low-cost incentives and cost-free text appeal interventions. Social Science Computer Review, 34(2), 229-43. https://doi.org/10.1177/0894439314563916

Kebede, M.A., Anbessie, B., \& Ayano, G. (2019). Prevalence and predictors of depression and anxiety among medical students in Addis Ababa, Ethiopia. International Journal of Mental Health Systems, 13(30). https://doi.org/10.1186/s13033-019-0287-6

Khanam, S.J., \& Bukhari, S.R. (2015). Depression As a Predictor of Academic Performance in Male and Female University Students. Journal of Pakistan Psychiatric Society, 12(2).

Kötter, T., Wagner, J., Brüheim, L., \& Voltmer, E. (2017). Perceived Medical School stress of undergraduate medical students predicts academic performance: An observational study. BMC Medical Education, 17(256). https://doi.org/10.1186/s12909-017-1091-0

Lee, D. (2019). The convergent, discriminant, and nomological validity of the Depression Anxiety Stress Scales-21 (DASS-21). Journal of Affective Disorders, 259, 136-42. https://doi.org/ 10.1016/i.jad.2019.06.036

Lovibond, P.F., \& Lovibond, S.H. (1995). Manual for the Depression Anxiety \& Stress Scales. (2nd Ed.). APA PsycTests. https://doi.org/ 10.1037/t39835-000

Mahoney, C.R., Giles, G.E., Marriott, B.P., Judelson, D.A., Glickman E.L., Geiselman, P.J., Lieberman, H.R. (2018). Intake of caffeine from all sources and reasons for use by college students. Clinical Nutrition, 38(2), 668-75. https://doi.org/10.1016/i.clnu. 2018.04.004

Marshall, L., Allison, A., Nykamp, D. (2008). Perceived stress and quality of life among doctor of pharmacy students. American Journal of Pharmaceutical Education, 72(6), 137. https://doi.org/ 10.5688/aj7206137

Mcllvain, G.E., Noland, M.P., \& Bickel, R. (2011). Caffeine consumption patterns and beliefs of college freshmen. American Journal of Health Education, 42(4), 235-44. https://doi.org/ 10.1080/19325037.2011.10599193

Mirón, J., Goldberg, X., López-solà, C., Nadal, R., Armario, A., Andero, R., Giraldo, J., Ortiz, J., Cardoner, N., \& Palao, D. (2019). Perceived Stress, Anxiety and Depression Among Undergraduate Students: An Online Survey Study. Journal of Depression and Anxiety, 8(1), 1-5. https://doi.org/10.26226/morressier.5b681 765b56e9b005965c249

Moreira de Sousa, J., Moreira, C.A., \& Telles-Correia, D. (2018). Anxiety, depression and academic performance: A study amongst Portuguese medical students versus non-medical students. Acta Medica Portuguesa, 31(9), 454-62. https://doi.org/10.20344/amp. $\underline{9996}$

Naquin, M.R., \& Gilbert, G.G. (1996). College students' smoking behavior, perceived stress, and coping styles. Journal of Drug Education, 26(4), 367-76. https://doi.org/10.2190/MTG0-DCCEYR29-JLT3
Nichter, M., Nichter, M., \& Carkoglu, A. (2007). Reconsidering stress and smoking: A qualitative study among college students. Tobacco Control, 16, 211-4. https://doi.org/10.1136/tc. $\underline{2007.019869}$

Nichter, M., Nichter, M., Carkoglu, A., Lloyd-Richardson, E., the Tabacco Etiology Research Netwirk (TERN). (2010). Smoking and drinking among college students: "It's a package deal." Drug and Alcohol Dependence, 106(1), 16-20. https://doi.org/10.1016/ j.drugalcdep.2009.07.025

Nuffic. (2017). Education system Nigeria. Available at: https:// www.nuffic.nl/en/publications/education-system-nigeria/

Nwachukwu, C., \& Onyenankeya, K. (2017). Use of Smartphones among College Students in Nigeria: Revelations and Reflections. Journal of Communication, 8(2), 171-82. https://doi.org/ 10.1080/0976691X.2017.1396007

Oduaran, C.A., \& Akanni, A.A. (2019). Perceived stress effect and socio-demographic factors in substance use: A study of undergraduate students in a South African university. Studies on Ethno-Medicine, 13(2), 17-21.https://doi.org/10.31901/24566772. 2019/13.02.586

Ogaji, J., Ojabo, C. (2014). Pharmacy education in Nigeria: The journey so far. Archives of Pharmacy Practice, 5(2), 47. https:// doi.org/10.4103/2045-080X.132644

Oh, C.-M., Kim, H.Y., Na, H.K., Cho, K.H., \& Chu, M.K. (2019). The Effect of Anxiety and Depression on Sleep Quality of Individuals With High Risk for Insomnia: A Population-Based Study. Frontiers in Neurology, 10(849). https://doi.org/10.3389/fneur.2019.00849

Olsen, F., Abelsen, B., \& Olsen, J.A. (2012). Improving response rate and quality of survey data with a scratch lottery ticket incentive. BMC Medical Research Methodology, 12(52). https:// doi.org/10.1186/1471-2288-12-52

Onigbogi, C., \& Banerjee, S. (2019). Prevalence of psychosocial stress and its risk factors among health-care workers in Nigeria: A systematic review and meta-analysis. Nigerian Medical Journal, 60(5), 238. https://doi.org/10.4103/nmj.NMJ 6719

Onyukwu, E., Clark, N., \& Ausukuya, C. (2017). Education System Profiles. Education in Nigeria - WENR - World Education News and Reviews. Available at: https://wenr.wes.org/2017/03/educationin-nigeria

Opoku-Acheampong, A., Kretchy, I.A., Acheampong, F., Afrane, B.A., Ashong, S., Tamakloe, B., \& Nyarko, A.K. (2017). Perceived stress and quality of life of pharmacy students in University of Ghana. BMC Res Notes. 10(115). https://doi.org/10.1186/ s13104-017-2439-6

Othman, N., Ahmad, F., Morr, C.E., \& Ritvo, P. (2019). Perceived impact of contextual determinants on depression, anxiety and stress : a survey with university students. International Journal of Mental Health Systems, 13(17). https://doi.org/10.1186/s13033-019-0275-x 
Penmetsa, G., \& Seethalakshmi, P. (2019). Effect of stress, depression, and anxiety over periodontal health indicators among health professional students. Journal of Indian Association of Public Health Dentistry, 17(1), 36-40. https://doi.org/10.4103/ jiaphd.jiaphd_53_18

Pettit, M.L., \& DeBarr, K.A. (2011). Perceived Stress, Energy Drink Consumption, and Academic Performance Among College Students. Journal of American College Health, 59(5), 334-41. https://doi.org/10.1080/07448481.2010.510163

Pharmacists Council of Nigeria. (2020). Benchmark and Minimum Academic Standard-Pharmaceutical Sciences. Available at: http:// www.pcn.gov.ng/files/BMS.pdf

Plichta, S.B., \& Kelvin, E.A. (2013). Munro's Statistical Methods For Health Care Research. 6th Ed. Wolters Kluwer Health, Lippincott Williams \& Wilkins

Rasheed, L. (2016). Prevalence and Correlates of Depression , Anxiety and Academic Stress among Science Students in Oduduwa University, Ile-Ife. Texila International Journal Public Health, 4(3), 1-11. https://doi.org/10.21522/TIJPH.2013.04.03.Art001

Richards, G., \& Smith, A. (2015). Caffeine consumption and selfassessed stress, anxiety, and depression in secondary school children. Journal of Psychopharmacology, 29(12), 1236-47. https://doi.org/10.1177/0269881115612404

Ryu, E., Couper, M.P., \& Marans, R.W. (2006). Survey Incentives: Cash vs. In-Kind; Face-to-Face vs. Mail; Response Rate vs. Nonresponse Error. International Journal of Public Opinion Research, 18(1), 89-106. https://doi.org/10.1093/ijpor/edh089

Sabourin, A.A., Prater, J.C., \& Mason NA. (2019). Assessment of mental health in doctor of pharmacy students. Currents in Pharmacy Teaching \& Learning, 11(3), 243-250. https://doi.org/ 10.1016/i.cptl.2018.12.004

Saravanan, C., \& Heidhy, I. (2014). Psychological problems and psychosocial predictors of cigarette smoking behavior among undergraduate students in Malaysia. Asian Pacific Organization for Cancer Prevention, 15(18), 7629-34. https://doi.org/10.7314/ APJCP.2014.15.18.7629

Saxena, S., Thornicroft, G., Knapp, M., \& Whiteford, H. (2007). Resources for mental health: scarcity, inequity, and inefficiency. The Lancet, 370(9590), 878-89. https://doi.org/10.1016/ s0140-6736(07)61239-2

Shaikh, B.T., Kahloon, A., Kazmi, M., Khalid, H., Nawaz, K., Khan, N., \& Khan, S. (2004). Students, stress and coping strategies: a case of Pakistani medical school. Educational Health (Abingdon), 17(3), 346-53. https://doi.org/10.1080/13576280400002585

Sohail, N. (2013). Stress and Academic Performance Among Medical Students. Journal of College of Physicians and Surgeons Pakistan, 23(1), 67-71.
Stallman, H.M. (2010). Psychological distress in university students: A comparison with general population data. Australian Psychology, 45(4), 249-57. https://doi.org/10.1080/00050067.2010.482109

Suleyiman, M., \& Zewdu, A. (2018). Prevalence and associated factors of stress among undergraduate students in Ambo University: Implication for Intervention. International Journal of Psychology and Counselling, 10(4), 29-39. https://doi.org/10.5897/ IJPC2018.0532

Sun, S.H., \& Zoriah, A. (2015). Assessing Stress among Undergraduate Pharmacy Students in University of Malaya. Indian Journal of Pharmaceutical Education and Research, 49(2), 99-105. https://doi.org/10.5530/ijper.49.2.4

Šabić L., \& Mujanović A. (2020). Smoking and Caffeine Consumption as Stress Coping Mechanisms in Medical Students. In A. Badnjevic, R. Škrbić, L. Gurbeta Pokvić (Eds.) IFMBE Proceedings, 73. Springer, Cham. https://doi.org/10.1007/978-3-030-17971-7_102

Talwar, P. (2016). The Goodness-of-Fit of Dass-21 Models Among University Students. Malaysian Journal of Public Health Medicine, 16(3), 219-26

Tanaja, N., Sachdeva, S., \& Dwivedi, N. (2018). Assessment of Depression , Anxiety, and Stress among Medical Students Enrolled in a Medical College of New Delhi, India. Indian Journal of Social Psychiatry, 34(2), 157-162

Uwakwe, R. (2019). Mental Health Service and Access in Nigeria: A Short Overview. International Journal of Global Social Work, 2(103). https://doi.org/10.15344/ijgsw/2018/103

Van Mol, C. (2017). Improving web survey efficiency: the impact of an extra reminder and reminder content on web survey response. International Journal of Social Research Methodology, 20(4), 17-27. https://doi.org/10.1080/13645579.2016.1185255

Votta, R.J., \& Benau, E.M. (2014). Sources of stress for pharmacy students in a nationwide sample. Currents in Pharmacy Teaching and Learning, 6(5), 675-81. https://doi.org/10.1016/j.cptl.2014.05.002

Vukomanovic, I., Kocic, S., Radovanovic, S., Mihailovic, N., Vasiljevic, D., \& Vukomanovic, V. (2017). The prevalence of cigarette smoking and its correlates of depressive and anxiety symptoms among university students in Central Serbia. Tobacco Prevention and Cessation, May(3). https://doi.org/10.18332/tpc/ $\underline{73697}$

WHO [World Health Organisation]. (2017). Depression and Other Common Mental Disorders Global Health Estimates. Available at: https://apps.who.int/iris/bitstream/handle/10665/254610/WHOMSD-MER-2017.2-eng.pdf

WHO \& Nigeria Ministry of Health. (2006). WHO-AIMS Report on Mental Health System in Nigeria. WHO and Ministry of Health, Ibadan, Nigeria. Available at: https://www.who.int/ mental health/evidence/nigeria who aims report.pdf?ua=1 
Wright, K.B. (2006). Researching Internet-Based Populations: Advantages and Disadvantages of Online Survey Research, Online Questionnaire Authoring Software Packages, and Web Survey Services. Journal of Computer-Mediated Communication, 10(3). https://doi.org/10.1111/j.1083-6101.2005.tb00259.x

Yousif, W., Wahed, A., Hassan, S.K., Yousif, W., Wahed, A., Hassan, S.K. (2019). Prevalence and associated factors of stress, anxiety and depression among medical Fayoum University students Prevalence and associated factors of stress, anxiety and depression among medical Fayoum University students. Alexandria Journal of Medicine, 53(1), 77-84. https://doi.org/10.1016/i.ajme.2016.01.005

Zegeye, A., Mossie, A., Gebrie, A., \& Markos, Y. (2018). Stress among Postgraduate Students and Its Association with Substance Use. Journal of Psychiatry, 21(3). https://doi.org/10.4172/2378$\underline{5756.1000448}$ 